\title{
DO RELATÓRIO À DECISÃO
}

"Todo problema passa, até sua solução, por três etapas: na primeira é ridículo, na segunda. combatido, na terceira, é óbvio."

SCHOPENHAUER

Uma das tarefas difíceis do administrador é avaliar os relatórios nos quais deve basear suas decisões. Sendo a economia de tempo uma das razões importantes para que o encargo de estudar um problema qualquer seja dado a terceiros - quer subordinados (linha e assessoria), quer pessoas e emprêsas especialmente contratadas (consultores e auditores ) - necessário se torna que o administrador esteja capacitado a analisar com precisão o relato resultante do estudo, a fim de poder, ràpidamente, aceitar ou rejeitar as recomendações que dêle constam, pois, do contrário, desaparece aquela vantagem de economia que pretende obter.

A primeira condição que a análise precisa para que seja feita com velocidade é a leitura rápida, arte que se ensina ao administrador em artigos, conferências e livros. (1) (2) E preciso, ainda, que o relatório seja escrito de acôrdo com as regras universais da boa comunicação, também expostas em livros e artigos diversos. (3)

KURT E. WEIL - Professor-Adjunto da Escola de Administração de Emprêsas de São Paulo, Departamento de Administração da Produção.

1) R. D. Altrick, "Preface to Critical Reading", Holt, 1956.

2) N. B. Smith, "Read Faster and Get More From Your Reading", Prentice-

Hall, 1958.

3) W. J. Gensler e K. D. Gensler, "Writing Guide for Chemists", McGrawHill Book Co., 1961. 
Supõe-se, em geral, que, preenchidos êsses dois requisitos, a transmissão de idéias - que é aquilo que realmente interessa ao administrador - se faça com facilidade, possibilitando o máximo de proveito da leitura.

\section{A LINGUAGEM E O RELATÓRIO}

Todavia, o relatório - que aqui entendemos no sentido lato, isto é, qualquer análise, comunicado ou memorandum escrito para servir de base a uma decisão - embora constituído de orações perfeitas, pode, muitas vêzes, ser um cristal deformado, quer por "tensões" tendenciosas, quer por impurezas "catalíticas".

Essa deformação está bem exemplificada nos comunicados emitidos pelos alemães na Segunda Grande Guerra, de 1943 a 1945. Nêles se dizia estarem êles "encurtando suas comunicações, diminuindo postos de difícil defesa, defendendo-se elàsticamente a partir de novas linhas de defesa preparadas com antecedência, aproximando frentes, anulando campos secundários de batalha para evitar dispersão de fôrças"... etc., sempre até a derrota final. Ora, êsses comunicados de guerra não estavam mentindo, mas contando a verdade enobrecida pela "arte de comunicações", arte que havia mesmo sido elevada ao nível de ministério (sob o título de "Volksaufklaerung", isto é, "esclarecimento do povo"). Sòmente quem se desse ao trabalho de verificar nos mapas a localização da nova linha de defesa - cem quilômetros aquém da anterior, por exemplo - poderia notar que a verdade comunicada encobria alguma coisa.

Hoje, noutro exemplo, as emprêsas industriais e comerciais do País emitem, anualmente, no ritual chamado "assembléia", o "relatório da diretoria", que acompanha o balanço e a conta de lucros e perdas. Salvo honrosas exceções, êsses relatórios ou inexistem, representando uma simples introdução para as contas, ou são um acumulado de lugares-comuns. Mesmo assim, contudo, devem ser examinados com cuidado, pois podem, se devidamente "traduzidos", dizer muita coisa uo administrador de tarimba. 
Consideremos alguns dos lugares-comuns mais encontradiços em tais relatórios:

Exemplos

A simplificação de nossa linha de produtos permitiu concentrar nosso esfôrço de vendas...

A expansão do crédito não acompanhou...

O rápido progresso da ciência torna obsoleto hoje o que ainda ontem foi a última palavra...

Calamidade:3 naturais não conseguiram afetar o funcionamento regular de nosso parque labril, graças aos estoques...

Estudos preliminares estão s€ndo feitos...
"Tradução"

Não produzimos o que não conseguimos vender.

Não temos dinheiro para pagar dividendes.

A concorrência está produzindo com custo menor.

Ainda bem que houve uma justificativa para o excesso de estoques.

Ninguém sabe do que se trata, mas estamos procurando averiguar.

É também verdade que diretores, gerentes e engenheiros-chefe conhecem as frases empregadas nos relatórios de pesquisa científica. Nesses relatórios, por si verdadøiras obras-primas de cuidado semântico, encontramos trases como "o rendimento previsto para o processo nôvo de fabricação parece extraordinàriamente elevado", o que nada significa, pois o "extraordinàriamente elevado" não é quantitativo e o "parece" exime de qualquer responsabilidade.

\section{A MATEMÁTICA NOS RELATÓRIOS}

Porém, não é só com palavras que os relatórios enganam administradores incautos. A matemática, também, serve com eficiência para tal finalidade, pois pode ser empregada com duplo efeito: o hipnótico e o "complexante".

Consegue-se o efeito hipnótico pela repetição de fórmulas e deduções. Desde que é possível supor que os administradores se dividam em duas classes, a primeira daqueles que entendem e a segunda daqueles que têm de dar a impressão que entendem de matemática, é necessário para ambos pelo menos correr a vista sôbre a série infindável 
de números, fórmulas e deduções. $O$ resultado é sempre um estado de sonolência hipnótica, que torna o individuo incapaz de raciocinar sôbre o que lê.

O efeito "complexante", que se obtém também pelo emprêgo profuso de quadros, tabelas e gráficos, decorre do primeiro, pois é fácil tornar admirado ou apavorado conforme entenda ou não de matemática - o administrador "hipnotizado" diante da sabedoria e profundidade sobejamente demonstradas por tantas fórmulas e deduções. Chega êle, então, à anulação mental: "Quem sabe tanto, não pode errar nas conclusões". Nesta situação, sòmente um administrador muito resistente verificará que pode haver erros, lógica, técnica e analiticamente.

Conhecemos, por exemplo, um relatório (ou panfleto) de 9 páginas que se destina a vender ações de uma emprêsa química brasileira. Nesse panfleto, os dados que procuram mostrar a importância do mercado de produtos químicos são norte-americanos, fato que é colocado fielmente; mas perdido na imensidão do relatório. As conclusões, após uma série de tabelas, induzem a um êrro - o valor calculado para a ação, no relatório, é baseado em número de ações já ultrapassado duas vêzes na data de emissão do prospecto e, portanto, o "sobrevalor" ali indicado na realidade não existe, o que se pode verificar apenas após estudo aprofundado.

\section{PRINCÍPIOS DE AVALIAÇÃO DE RELATÓRIOS}

A análise de um relatório pressupõe, por parte do administrador, o conhecimento de uma série de princípios, que são aplicados consciente ou inconscientemente. Dentre êles, destacamos dois que são universais, além de particularmente importantes.

O primeiro dêles é o princípio da integração, que pode ser enunciado da seguinte maneira: "a emprêsa é uma entidade integrada; assim, a modificação num de seus setores afeta, necessàriamente, todos os demais, em prazo mais ou menos curto." Exemplifiquemos: um dos diretores de 
certa emprêsa paulista que necessitava diminuir seus custos de produção para poder concorrer no mercado contratou os serviços de um engenheiro de produção como consultor e, após três meses, recebeu um excelente relatório, que entregou a outro técnico do mesmo ramo para avaliação.

A conclusão a que se chegou era de que o plano era perfeito, estando acima de qualquer suspeita de falha: a introdução de um incentivo salarial, após estudo de tempo, daria maior produtividade individual; os custos de produção cairiam, porque o mesmo número de homens fabricaria mais unidades, distribuindo os custos fixos e os da mão-de-obra por maior produção. A emprêsa poderia, então, decidir se ficaria com número igual de empregados, produzindo mais, ou com menor número, produzindo o mesmo, a menor custo.

O relatório foi seguido: a emprêsa pôs a vigorar o incentivo salarial, após estudo de tempo, tendo a produção aumentado de $40 \%$. Consequientemente, faltou matéria-prima, que teve de ser comprada às pressas. (A alternativa seria despedir $30 \%$ da mão-de-obra e para isso não havia dinheiro em caixa.) Com o aumento de produção aumentou o estoque, faltou capital circulante, foi necessário contrair um empréstimo a fim de que fôsse possível continuar a produzir. As vendas tiveram de ser incentivadas, o que significou um esfôrço de propaganda custoso e mal planejado, por falta de tempo.

A emprêsa só conseguiu regularizar sua situação após seis meses de improvisação, simplesmente porque o plano, que era excelente do ponto de vista da produção, não foi integrado na totalidade da emprêsa. Antes de sua execução, deveriam ter sido providenciadas reservas para a compra de matéria-prima, a dispensa de operários e a campanha de publicidade, bem como planos de publicidade e de vendas.

A avaliação de qualquer relatório fica, assim, na dependência da integração de todos os dados, uma vez que, no 
ămbito da emprêsa, raras vêzes é possível isolar um só fato.

O segundo princípio, o de prós e contras, pode ser assim enunciado: "a qualquer fôrça corresponde uma reação e a qualquer opinião uma contrária (no mínimo)." De acôrdo com êsse princípio, o administrador pode procurar por si mesmo os diversos lados de cada questão controvertida, ou levar o problema, numa reunião, a um grupo de colaboradores que então discutem - e possìvelmente iluminam - todos os seus ângulos. Ilustremo-lo com um exemplo: grande emprêsa de produtos químicos e farmacêuticos está diante do problema de incentivar a venda de seus produtos químicos a novos fregueses. O relatório do diretor de vendas ao presidente recomenda um nôvo tipo de venda para produtos químicos industriais: um corpo de propagandistas semelhante ao do propagandista-médico para visitar todos os eventuais fregueses e fazer publicidade, deixando o campo livre para os vendedores comuns.

A reunião da diretoria serviu para pesar os prós e contras dos seguintes pontos:

a) - custo do estabelecimneto de um corpo de propagandistas técnicos em relação ao lucro eventual decorrente da maior venda;

b) - facilidade de planejamento de visitas de propagandistas, trabalhando de acôrdo com planos e não de solicitação repentina de fregueses, como os vendedores comuns; c)

c) - problemas originados pelo maior número de fregueses alcançados por propagandistas; fregueses que só podem ser alcançados por visita pessoal, ou intermedianios como única solução.

Após longa discussão, essa emprêsa aceitou a idéia dos propagandistas e teve sucesso: o custo de distribuição subiu, mas o desenvolvimento de novos mercados permitiu um aumento de $30 \%$ na produção, que se distribuiu entre $50 \%$ a mais de fregueses - resultado considerado satisfatório, pois o lucro total da emprêsa aumentou. 
TÉCNICAS DE AVALIAÇÃo: PERFIL DE HARRIS

Os dois princípios acima foram reunidos numa técnica aperfeiçoada por JOHN S. HARRIs, da "Mionsanto Chemical Co.", de Saint Louis, Missouri, U.S.A. (4)

HARRIS divide sua análise em seções: "aspectos financeiros", "aspectos de produção e engenharia", "aspectos de pesquisa e desenvolvimento" e "aspectos mercadológicos e de produtos". Em cada uma dessas seções coloca uma série de itens. Dentro de "aspectos financeiros", há os itens "Amortização", "Lucros sôbre o Capital" etc. Cada item recebe quatro subdivisões, de valor $-2,-1,+1$ e +2 . Assim, no item "Lucro", temos o seguinte:

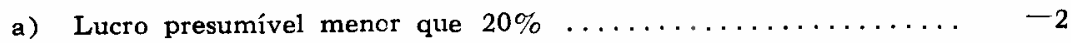

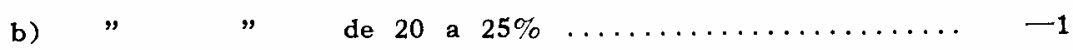

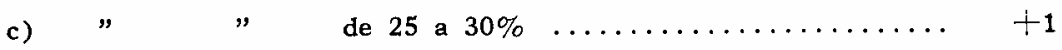

d) $" \quad$ acima de $30 \% \ldots \ldots \ldots \ldots \ldots \ldots \ldots+2$

No caso do lucro presumível, a resposta é única. Muitas vêzes, porém, a resposta no perfil pode ser múltipla. No item "Matéria-prima", por exemplo, temos as seguintes subdivisões:

a) Limitação de matéria-prima cu poucos fornecedores $\ldots \ldots \ldots \ldots-2$

b) Pequena quantidade disponível na própria emprêsa $\ldots \ldots \ldots \ldots \ldots$

c) Pode fàcilmente ser comprada de fornecedores externos ....... +1

d) Existe na emprêsa em quantidade suficiente $\ldots \ldots \ldots \ldots \ldots \ldots+2$

Neste caso, $a$ e $b$ podem aparecer simultâneamente, como também $b$ e $c$.

HARRIS emprega o perfil para análise da produção e da venda de produtos ao consumidor. Acreditamos que sua posição como diretor do planejamento econômico da Monsanto ("Organic Division") tenha tido influência sôbre o que considerou no perfil. De nossa parte, sentimos falta

4) John S. Harris, "New Product Profile Chart", "Chemical and Engineering News", 39, april 17, 1961, págs. 110-118. 
de apreciações sôbre pessoal, onde proporíamos, por exemplo:

\section{Item: "Pessoal técnico"}

a) Difícil de encontrar $\ldots \ldots \ldots \ldots \ldots \ldots \ldots \ldots \ldots \ldots \ldots \ldots \ldots \ldots \ldots \ldots \ldots, 2$

b) Disponível no metcado, mas muito caro, pois está empregado .. -1

c) Disponível em parte na emprêsa, em parte no mercado $\ldots \ldots \ldots+1$

d) Dispcnivel na emprêsa $\ldots \ldots \ldots \ldots \ldots \ldots \ldots \ldots \ldots \ldots \ldots \ldots \ldots \ldots \ldots \ldots \ldots \ldots \ldots$

Item: "Mão-de-obra"

a) Precisa ser atraída de outros empregos $\ldots \ldots \ldots \ldots \ldots \ldots \ldots \ldots-2$

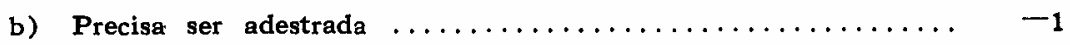

c) Fácil de encontrar no mercado $\ldots \ldots \ldots \ldots \ldots \ldots \ldots \ldots \ldots \ldots+1$

d) Disponivel na emprêsa $\ldots \ldots \ldots \ldots \ldots \ldots \ldots \ldots \ldots \ldots \ldots \ldots \ldots \ldots \ldots \ldots \ldots \ldots$

Faltam também aspectos de localização de emprêsas, de impostos e taxas ligados ao produto e muitos outros. Isso quer dizer que, ao menos parcialmente, os itens a considerar devem ser estabelecidos para cada emprêsa e cada caso em particular, não sendo necessàriamente aquêles 26 , em quatro subdivisões, que aparecem no artigo de HARRIS. (5)

No Quadro 1, reproduzimos um dos exemplos usados por HARRIS para aplicação do perfil, neste caso para o problema de acréscimo de um nôvo produto à linha existente. Para fazer a análise, HARRIS estabelece quatro colunas e tantas linhas quantos itens usa na análise. As colunas recebem as indicações $-2,-1,+1 \mathrm{e}+2$. Os quadrados estabelecidos pelas linhas e colunas são coloridos de vermelho quando colocados no lado negativo e em prêto quando no positivo.

5) Para os que se interessem, Reprint Dept., ACS Applied Publications, 1155 Sixteenth Street, N.W. Washington 6, D.C., Estados Unidos, tem à venda cópias avulsas do artigo. 
Faz-se a análise pela observação do número e da colocação dos quadrados vermelhos e prêtos. Abundância dos primeiros significa perigo. Mas também um pequeno número dêles, concentrados numa única seção, pode aconselhar o abandono do projeto. Assim, quadrados vermelhos na rentabilidade e na amortização podem liquidar um projeto aparentemente bom sob outros aspectos.

De acôrdo com HARRIS, o ponto importante na avaliação é a seqüência de análises pelo perfil. Antes do início de um projeto é feito o primeiro perfil; seguem-se a êsse tantos quantas sejam as etapas de desenvolvimento do projeto e finalmente um último após o início das vendas ou da produção. Êsse tipo de análise permite parar quando se note o desvio do perfil para o setor vermelho, que foi o que se verificou no caso apresentado no Quadro 1 .

TÉCNICAS DE AVALIAÇÃO: FIXAÇÃo DE VARIÁVEIS

$\mathrm{Na}$ avaliação de um relatório com valôres numéricos, sejam êles de venda, produção ou finanças, recomenda-se um antigo método de pesquisa empregado em física e química. Fazendo constantes tôdas as variáveis exceto uma, observa-se o comportamento do conjunto no crescimento e no decréscimo de um dos fatôres.

Assim, se se quiser fazer uma previsão de vendas com base no relatório de uma campanha de propaganda, dever-se-á supor que será possível alcançar essas vendas, que haverá possibilidade de fazer a propaganda, que existirão matéria-prima, mão-de-obra e máquinas para a produção, empregando-se, então, a técnica de separação de variáveis: que acontecerá do ponto de vista de despesas e de custo, quando as vendas caírem abaixo do previsto? Idem, se forem excessivas as vendas? A produção é suficiente? Se houver queda de 5,10,15 e 20\% da produção, que acontecerá às vendas? Às finanças? Aos compromissos de pagamento etc.?

A desvantagem do método de manter constantes tôdas as suposições menos uma e de observar o reflexo que a va- 
riação dessa traz a cada uma das demais está, òbviamente, na sua complexidade e, portanto, no tempo que exige. Por isso, é especialmente interessante para emprêsas que possuam cérebro eletrônico ou possam alugar um serviço de computador de emprêsas como a "IBM", e "SPEED" (Buell) e outras. (6)

Dentro de uma análise de computador é possível, na decisão "comprar ou fazer", por exemplo, conhecer os efeitos do grau de utilização de máquinas, necessidade de mão-de-obra, impostos, distribuição de custos fixos, desgastes de máquinas etc. A melhor alternativa pode, então, ser matemàticamente escolhida. $O$ método usado é o de investimento (relação de lucro) e os resultados são impressos para cada tipo de investimento proposto e suas alternativas. (7)

Ora, havendo 56 computadores eletrônicos no Brasil em fins de 1961, (8) deve ser possível para muitas emprêsas nacionais o uso de um sistema de análise que permita verificar conclusões de relatórios em cérebros eletrônicos, com programa adaptado a seu problema e seus métodos.

Essa análise, porém, possui um lado negativo. WEAVER considera a avaliação econômica e de lucro como sòmente parte do processo de tomada de posição, pois a decisão final deve ficar ainda com o administrador. (9) Desde que o jôgo de avaliar o avaliador deve terminar em certo momento, nenhum programa pode substituir a visão global do empresário. Dando aos números a importância devida, deve o administrador tomar sua decisão e esperar as conseqüências.

6) A "IBM" oferece um programa de computador relativo a alternativas de investimento de capital. De acôrdo com os anúncics da própria IBM, o programa responde a perguntas como: consertar ou substituir equipamento? Que campo de pesquisa poderá dar melhores resultados financeiros? Fabricar ou comprar peças? Deve ser aumentada a prcdução? Qual o melhor sistema de distribuição?

7) Segundo anúncio da "IBM" em "Chemical Engineering", 69, n. ${ }^{\circ}$, april 16, 1962, págs. 8 e 9 .

8) Time, december 29, 1961 , pág. 54.

9) James B. Weaver, diretor da "Atlas Chemical Industries", em conferência perante a "Commercial Chemical Development Association", Chicago, Ill. Reportagem de "Chemical \& Engineering News", october 30, 1961, pág. 28. 
Em alguns casos, é possível usar gráficos, como o do pontu de paridade, (10) para análise de dados que servem de base para decisões. Os gráficos contínuos, porém, mostram sòmente parte da realidade. Uma companhia siderúrgica, por exemplo, pode ter em funcionamento um, dois, ou muitos altos-fornos. Cada forno terá produção ótima de rendimento máximo. Se o limite de produção de um alto-forno fôr de mil toneladas e o seu rendimento ótimo estiver em 900 toneladas/dia, para produzir 1.200 toneladas haverá necessidade de investimento adicional de um forno; em seguida, dois fornos deverão produzir abaixo de sua capacidade ótima, com um investimento de capital desproporcional ao aumento de vendas conseguido. $\mathrm{Ca}$ racteriza-se, assim, a falta de "elasticidade de decisão", que torna necessárias ampliações em saltos em muitas indústrias.

Elasticidade de decisão é, pois, a propriedade de haver reversibilidade de despesas nas decisões. Ela não existe quando, para um incremento de uma unidade de produção, haja necessidade de um incremento desproporcional de meios de produção, tanto em mão-de-obra quanto em unidades produtoras. Essa expansão é inelástica, pois os custos fixos do aumento continuarão pesando mesmo quando diminua a produção.

A falta de elasticidade foi demonstrada, noutro exemplo, em uma emprêsa de rações animais cuja produção, em três turnos, seis dias por semana, era de 900 toneladas/ mês. Tendo aumentado a concorrência no mercado, supôs a diretoria da emprêsa que a melhor solução seria a suposição de perda de um têrço do mercado. Baseada nessa premissa, dispensou uma das três turmas do rodízio da mão-de-obra.

Todavia, a produção reduzida a 600 toneladas/dia era insuficiente: havia necessidade de 750 toneladas para

10) Grant \& Ireson, "Handbook of Industrial Enginoering and Managemont", Prentice Hall, 1955, pág. 62 escuintes, pág. 1112 e seguintes. 
atender aos pedidos recebidos. Não havia possibilidade de trabalhar com meio turno, pois a maquinaria era contínua. Não era possível trabalhar durante um mês com uma turma noturna e outro não, devido à legislação do trabalho. A decisão tomada de estocar mensalmente um excesso de 150 toneladas significava capital prêso. Essa solução trouxe como consequiência um aumento do esfôrço de venda para colocar o excesso da produção mensal.

CONCLUSÕES

Pelo exposto se verifica que é ainda ao administrador que cabe a avaliação do imponderável, sempre presente nos dados fornecidos em relatórios. Porém, facilitada a tarefa de analisar o ponderável e tomadas as precauções que aqui mencionamos para que essa análise seja objetiva e precisa, está aberto o caminho para decisões mais eficientes e inteligentes.

Assim, cremos que, atentando para os princípios que devem reger a avaliação das opiniões resultantes de estudos e acautelando-se contra a fascinação do linguajar floreado mas inconsistente $\mathrm{e}$ a hipnose da presença de números bem dispostos mas irrelevantes ou ilusórios, está o administrador preparado para tomar suas decisōes, com a firmeza e a coragem que devem ser seu apanágio - firmeza e coragem que são, de acôrdo com o "Pequeno Dicionário da Língua Portuguêsa", sinônimas de decisão. 